\title{
Consumo de drogas en el cine de Pedro Almodóvar
}

\author{
Sánchez-Carbonell, X.; Colomera, P. \\ Facultat de Psicologia i Ciències de l’Educació Blanquerna. Universitat Ramon Llull. Barcelona. España.
}

Enviar correspondencia:

Dr. Xavier Sánchez-Carbonell. Facultat de Psicologia i Ciències de l’Educació Blanquerna. Universitat Ramon Llull. C/ Císter, 34.08022 Barcelona, España. Teléfono 9325330 00. E-mail: xaviersc@blanquerna.url.es

\section{RESUMEN}

Objetivo: Análisis del consumo de drogas legales e ilegales en las películas dirigidas por el cineasta Pedro Almodóvar. La finalidad es indagar cómo el cine contribuye a crear una imagen de las drogas.

Método: Se estudiaron los tipos de sustancias, la diferencia entre géneros, las clases de consumo / vías de administración, los personajes prototipos, los contextos de consumo y la actitud del director frente al tema, mediante plantillas de observación diseñadas específicamente para esta investigación.

Resultados y Conclusiones: Se observa la presencia de drogas en los trece films de P. Almodóvar. Se dedicaron 150 minutos a las drogas legales y 30 a las ilegales. Las mujeres consumen más drogas que los hombres, no existe un patrón único de consumidor y las únicas drogas que generan dependencia, son el alcohol, el tabaco y la heroína. Aunque Almodóvar siempre es permisivo con el consumo de cocaína y alcohol, la imagen de la heroína cambia al final de su trayectoria. En resumen, para Almodóvar el consumo de drogas y la adicción a las mismas no es un tema central sino un recurso para caracterizar personajes y contextos. Por último, no se debe infravalorar el riesgo de que las productoras cinematográficas redondeen sus ingresos por medio de la publicidad encubierta de marcas de alcohol y tabaco.

Palabras clave: Almodóvar, cine, actitud hacia las drogas, representación social, diferencias de género.

\section{ABSTRACT}

Aims: To analyse the legal and illegal drug taking in films directed by Pedro Almodóvar. The objective is to ascertain how the cinema contributes to creating an image of drugs.

Method: To study drug types, gender differences, drugtaking types, administration ways, prototype characters, consumption's context and director's attitude in front of drugs. Using structured observational techniques designed specifically.

Findings and Conclusions: The presence of drugs is to be observed in thirteen films by Pedro Almodóvar. 150 minutes were devoted to legal drugs and 30 to the illegal ones. Women consume more drugs that men, there is no single pattern of a user and the only drugs that generate dependency are alcohol, tobacco and heroin. Although Almodóvar is always permissive about the consumption of cocaine and alcohol, the image of heroin changes at the end. To summarise, drug use and addiction is not a central subject for Almodóvar but a resource to characterise people and contexts. Finally, the risk that films increase their revenue through the hidden publicity given to brands of alcohol and tobacco should not be underestimated.

Key words: Almodóvar, cinema, drugs attitude, social representation, gender difference.

\section{CONSUMO DE DROGAS EN EL CINE DE PEDRO ALMODÓVAR}

$\mathbf{L}$ os medios de comunicación social y las vías de expresión cultural juegan un papel fundamental en la formación de la opinión social sobre el consumo de drogas. En fenómenos como las adicciones, el cine es fiel reflejo de la sociedad que ha producido y consumido las películas (Rodríguez, 2000) y es, a su vez, factor influyente en la construcción social de opinión. La ficción es, de alguna manera, un reflejo de las preocupaciones, obsesiones y temores de la sociedad ante la droga (Costa y Pérez, 1989). El poder de comunicación del cine le hace particularmente sensible a todo tipo de controles y manipulaciones, que tienen como objetivo final, crear y conformar la realidad que 
más conviene a la sociedad (Uris, 1995). El cine contribuye a transformar la realidad, no es documental sobre 'el mundo de la droga', y como expresión artística y cultural ofrece su visión particular sobre el tema (Sánchez-Carbonell, 1999).

Varios autores han estudiado la aportación del cine a la creación social de opinión y actitudes sobre drogas. Hazan, Lipton y Glantz (1994) y Stockwell y Glantz (1997) investigaron la presencia del tabaco en el cine y encontraron que su consumo había sufrido cambios poco significativos desde 1960 a 1990. Observaron que el descenso en el consumo de tabaco en la sociedad norteamericana en aquellos años no se reflejaba en una disminución en el mundo del celuloide. Por su parte, Carnall (1998) mostró que mientras en la sociedad disminuía el consumo de tabaco, su presencia aumentaba en las películas, basándose en un estudio que analizaba las diez películas más taquilleras en EE.UU de 1990 a 1995. A su vez, las características que el tabaco otorga a sus consumidores habían evolucionado, de ser un detonante de glamoury de atractivo sexual en los años cuarenta y cincuenta a convertirse en una actividad diaria y normalizada, sin llevar asociada consecuencias negativas.

Stockwell (1998) afirma que a través de las películas se transmiten mensajes, particularmente dirigidos a los jóvenes, de que el uso del tabaco es una conducta ampliamente extendida y aceptada. Este tipo de mensajes se ven continuamente respaldados por las grandes industrias tabaqueras, propagando lemas tales como rebelión e independencia. Everett, Schunth y Tribble (1998), tras analizar diez superproducciones norteamericanas comprendidas entre 1985 y 1995, hallaron que los peligros que conlleva el uso y/o abuso del tabaco y el alcohol no están reflejados en las conductas de los personajes cinematográficos que son modelos potenciales a seguir por la juventud de Estados Unidos. En opinión de Roberts, Henriksen, Christenson y Kelly (1999) muchas películas tienden a legitimizar, normalizar, trivializar o glorificar el consumo de drogas y sugerir a los jóvenes que esta conducta no tiene consecuencias negativas.

En 1998, Mclntosh, Bazzini, Smith y Wayne examinaron la imagen que ofrecen los actores al gran público en sus películas según la variable fumador / no fumador. Al estudiar las características que presentan los personajes fumadores y la evolución del consumo de tabaco a lo largo del tiempo, encontraron que los fumadores eran presentados de manera más romántica, sexualmente más activos y más inteligentes que los personajes no fumadores. Aún así, los fumadores no se diferencian de los no fumadores en aspectos como el atractivo personal, la bondad, el estado socioeconómico, la agresividad o la simpatía. Su conclusión más sobresaliente es que la representación y el uso de tabaco en las películas de Hollywood tiende a ignorar las consecuencias negativas del mismo.
Goldstein, Sobel y Newman (1999), estudiaron la presencia de alcohol y tabaco en una muestra de 50 películas de dibujos animados dirigidas al público infantil, producidas entre 1937 y 1995 por cinco de las mayores compañías cinematográficas de EE.UU. Hallaron que 34 de las películas (68\%) contenían al menos una escena relacionada con el tabaco y/o el alcohol; 28 (56\%) representaban más de uno de estas escenas; y, 25 (50\%) incluían el uso de alcohol de forma reiterada. Fumaron 76 personajes durante 45 minutos y bebieron, 63 personajes durante 27 minutos. Los personajes "buenos" no se diferenciaban de los "malos" por el uso de sustancias adictivas. De todo ello, concluyeron que más de dos tercios de las películas animadas para menores hacían uso del alcohol y del tabaco en sus argumentos, sin establecer mensajes verbales claros sobre los efectos negativos que produce el uso y el abuso de este tipo de sustancias a largo plazo.

Roberts, Henriksen, Christenson y Kelly (1999) examinaron la frecuencia y la naturaleza del consumo de drogas en las películas más alquiladas en vídeo-clubs en Estados Unidos entre 1996 y 1997. Concluyeron que aunque la presencia de sustancias adictivas a lo largo de la muestra analizada era muy vasta sólo una mínima parte de ellas tenía como tema central la drogadicción. Las drogas legales aparecían en la mayoría de películas independientemente del género cinematográfico, mientras que las sustancias ilícitas tendían a ser expuestas en dramas.

Cuando se investigó la presencia de marcas de tabaco en las 25 películas más taquilleras en Estados Unidos, desde 1988 hasta 1997, se concluyó que la presencia de éstas en la gran pantalla era habitual y cada vez más común (Sargent, Tickle, Beach, Dalton, Ahrens y Heatherton, 2001).

Este tipo de estudios también se ha realizado en latinoamericana. González y Donaire (1986) realizaron una investigación sobre cinco films latinoamericanos (dos cubanos, dos mejicanos y uno argentino), producidos durante los años ochenta. Su objetivo fue estudiar el modelo de pautas de ingestión alcohólica y los patrones de consumo etílico reflejados, así como los objetivos del uso y/o abuso del alcohol, la intencionalidad argumental y el tiempo dedicado a escenas relacionadas con esta temática. Del estudio se desprendió que el tiempo dedicado al consumo de bebidas etílicas era tres veces mayor que el tiempo dedicado a bebidas no alcohólicas, que el uso/abuso de alcohol tuvo como objetivo mayoritario afrontar frustraciones y la desinhibición personal y que destacaba una actitud social de aceptación del consumo etílico. En 1988, González y Cisneros Ilevaron a cabo un estudio comparativo entre 16 películas cubanas y de otros países latinoamericanos. Encontraron que era mayor en ambas muestras el tiempo dedicado al consumo de alcohol que el dedicado a las bebidas no 
alcohólicas. En las producciones cubanas se reflejaba una mayor tendencia a vincular el uso de alcohol a celebraciones, amistad y relaciones amorosas; mientras que en el otro grupo de películas, prevalecía la ingesta de alcohol con el objetivo de superar las frustraciones. Los dos grupos de películas reflejaban actitudes de tolerancia frente al uso y abuso de alcohol.

Este panorama subraya la importancia del cine en la formación de opinión y actitudes hacia las drogas y muestran cómo puede influir en la conceptualización social del fenómeno. Por ello, en este estudio se pretende analizar la obra de Pedro Almodóvar, uno de los directores españoles más representativos y populares de la última década, con una media de 1.046.236 espectadores por película (3.344.640 personas vieron "Mujeres al borde de un ataque de nervios") y una media de recaudación de 2.799.053 euros.

A finales de los años setenta, Pedro Almodóvar pertenecía a una compañía de teatro, redactaba textos para fotonovelas, era compositor y cantante, colaboraba en revistas y realizaba cortometrajes, mientras trabajaba como administrativo en una empresa de telecomunicaciones (García y Maldonado, 1989; Holguín, 1994). Con el cambio de década, Almodóvar se convirtió en una figura indiscutible de la llamada 'movida madrileña', movimiento contrario a la cultura heredada y a las figuras que la representaban. En la confluencia de la década de los setenta con los ochenta, una serie de creadores, representantes de al menos dos generaciones, desplegaron en Madrid un conjunto de propuestas vitales y estéticas que de manera espontánea, renovaron el panorama de la música, el cine, las artes plásticas, la moda y los comportamientos urbanos, convirtiendo Madrid en emblema máximo de la modernidad (Gallero, 1991). Su permanente interés por las derivaciones de la cultura pop, por los fenómenos kitsch, por el cómic, la homosexualidad, la moda, la droga o el melodrama, se consolidaron en su primer largometraje "Pepi, Luci, Bom y otras chicas del montón". Después de éste, Ilegaron otras películas premiadas y reconocidas por muestras de cine extranjeras, convirtiéndolo en el cineasta español con mayor resonancia internacional. Con "Mujeres al borde de un ataque de nervios", su reconocimiento llegó también a España, fue nominado para el Oscar a la Mejor Película de habla no inglesa (1988) y ganó el premio Goya al Mejor Guión Original. A partir de ahí, se suceden con parecido éxito sus títulos siguientes, destacando sin embargo su última creación, "Todo sobre mi madre", que recibió el Oscar a la Mejor Película de habla no inglesa (1999) y siete premios Goya, entre los que destacan los de Mejor Película y Mejor Director. Una característica importante de la obra de Almodóvar es que en calidad de guionista, director y productor tiene más control del que suele ser habitual, sobre el mensaje que quiere expresar. De este modo, Almodóvar ha logrado convertirse en uno de los directores españoles más famosos y de mayor reconocimiento internacional. Las drogas y las adicciones están siempre presentes en su cine, a menudo presentadas de modo caricaturesco (Strauss, 2001).

El objetivo de este trabajo es analizar el consumo de sustancias adictivas en la filmografía de Pedro Almodóvar. En concreto se pretende describir su presencia, las características de los personajes consumidores y la actitud hacia los diferentes tipos de sustancias.

\section{MÉTODO}

\section{Muestra}

La muestra está formada por los 13 largometrajes dirigidos por Pedro Almodóvar desde 1980 hasta 1999: "Pepi, Luci, Bom y otras chicas del montón" (1980); "Laberinto de pasiones" (1982); "Entre tinieblas" (1983); " ¿Qué he hecho yo para merecer esto?" (1984); "Matador" (1985); "La ley del deseo" (1987); "Mujeres al borde de un ataque de nervios" (1988); "¡Átame!" (1989); “Tacones Lejanos" (1991); "KiKa" (1993); "La flor de mi secreto" (1995); "Carne Trémula" (1997) y; "Todo sobre mi madre" (1999). Los trece largometrajes están disponibles en formato vídeo.

\section{Variables}

Las variables estudiadas fueron: a) duración de las escenas en las que se consume, alude o aparecen drogas; b) tipo de droga legal (alcohol; tabaco; psicofármacos: benzodiacepinas, antidepresivos, anfetaminas y barbitúricos; estimulantes menores: café y té) o ilegal (cannabis; heroína y derivados opiáceos; cocaína; alucinógenos); c) vía de administración; d) personajes consumidores (género; edad; protagonista/secundario; papel desarrollado dentro del film; situación o motivo de consumo); e) contexto de consumo y; f) actitud respecto al consumo (favorable o desfavorable).

\section{Material y procedimiento}

Las variables se analizaron mediante el uso de plantillas diseñadas específicamente para esta investigación. En la primera, dedicada al personaje consumidor, se analizaba su sexo, edad aproximada y papel desarrollado en la película. La segunda plantilla estaba centrada en el tipo de sustancia adictiva consumida y su vía de administración, la tercera examinaba el contexto y la situación de consumo y la cuarta, la duración de las escenas. 


\section{RESULTADOS}

\section{Presencia}

El consumo de drogas apareció o se mencionó en los trece films. El tiempo dedicado a las sustancias adictivas fue de 3 horas 5 minutos 39 segundos, lo que representa un $14 \%$ de la duración total de los 13 largometrajes (21 horas 58 minutos) y osciló entre los 26 minutos de "Entre tinieblas" y los 4 minutos de "Matador". Al estudiar por separado las drogas legales de las ilegales, se observó que las legales aparecieron en todos los films (2 horas 39 minutos 14 segundos), oscilando entre los 3 minutos de "Matador" y los 23 minutos de "Laberinto de pasiones". Las ilegales figuran en todos los films excepto en "Mujeres al borde de un ataque de nervios" y "KiKa" con una presencia total de 26 minutos y 25 segundos (Figura 1).

Figura 1. Tiempo de presencia de drogas legales e legales en la filmografía de Pedro Almodóvar, por tiempo dedicado.

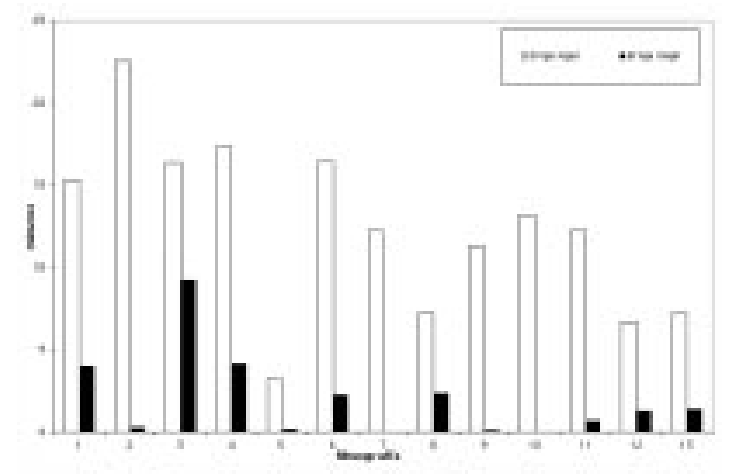

Filmografía 1, Pepi, Luci, Bom y otras chicas del montón; 2, Laberinto de pasiones; 3, Entre tinieblas; 4, ¿Qué he hecho yo para merecer esto?; 5, Matador; 6, La ley del deseo; 7, Mujeres al borde de un ataque de nervios; 8 , ¡Átame!; 9, Tacones lejanos; 10, Kika; 11, La flor de mi secreto; 12, Carne trémula; y 13, Todo sobre mi madre.

\section{Tipo de droga}

El tipo de droga presente en la obra de Almodóvar se muestra en la Figura 2 y puede resumirse de la siguiente manera:

Tabaco. Representa el 34\% (1 hora 7 minutos 4 segundos) del total de las sustancias adictivas y el $39 \%$ del total de las drogas legales. Su consumo o alusión esta presente en todas las películas.

Alcohol. Las bebidas alcohólicas configuran el $36 \%$ (1 hora 11 minutos 8 segundos) del total de drogas y el $41 \%$ de las drogas legales. Aparece en toda la filmografía de Almodóvar.

Psicofármacos. En 11 de los 13 largometrajes se consumen psicofármacos. Representan el 7\% (13 minutos 53 segundos) del total de sustancias adictivas y un $8 \%$ del total de drogas legales.

Estimulantes menores. El café aparece en 10 de las 13 películas con una duración de 19 minutos 35 segundos. El té solo aparece en dos films durante 1 minuto 2 segundos. Los estimulantes menores representan un $10 \%$ del total de drogas y un $12 \%$ dentro del conjunto de drogas legales.

Heroína y derivados. Es la droga ilegal más frecuente de la obra de Almodóvar, presente en 8 de sus 13 películas. Representa el $6 \%$ (11 minutos 34 segundos) del total de droga y el $48 \%$ del total de droga ilegal.

Cocaína. Es la segunda droga ilegal más representada. Aparece en 6 films. Configura el 3\% 6 minutos, 21 segundos) del total de drogas y el $26 \%$ del total de droga ilegal.

Cannabis. El hachís y la marihuana, configuran el $3 \%$ (5 minutos 31 segundos) del total de drogas y el $22 \%$ del total de drogas ilegales. Aparece en siete películas.

Alucinógenos. Aparece un 1\% (1 minuto 17 segundos) y un $4 \%$ sobre el conjunto global de drogas ilegales.

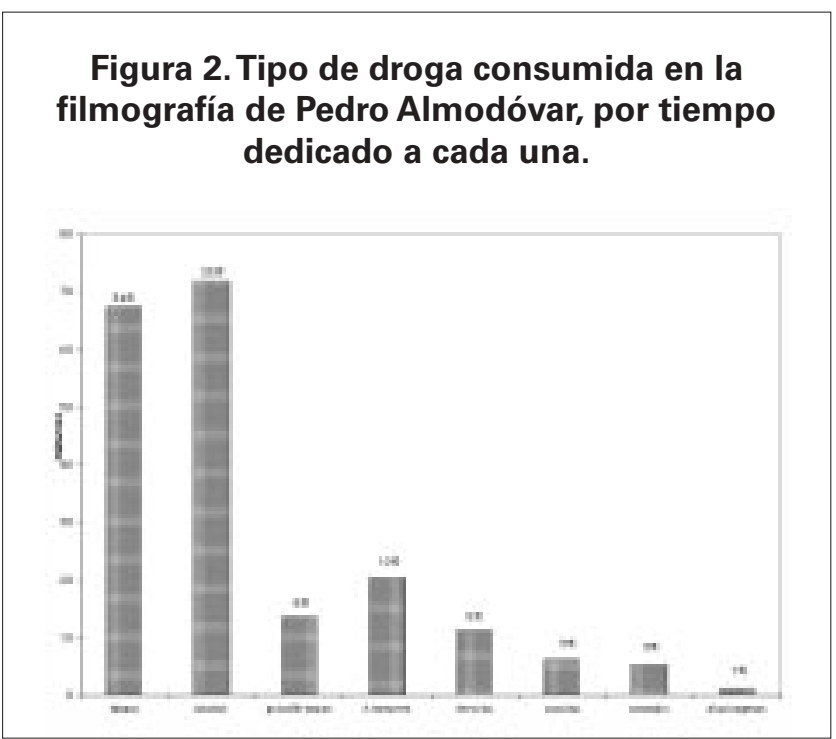

\section{Características del consumo}

Tabaco. Su consumo es natural y normalizado, sin posibles actitudes contrarias o punitivas. Se consume en todo tipo de situaciones y lugares, aunque en ocasiones, el contexto puede resultar inapropiado (por ejemplo, un sacerdote fuma oficiando misa en "Entre Tinieblas"). A menudo, se usa como ansiolítico en situaciones de estrés o para caracterizar la personali- 
dad de un personaje (por ejemplo: Sofía fuma al encontrarse a las monjas en el mercado, dotándola este hecho de un cierto aire de elegancia, en "Entre Tinieblas"). Cabe destacar que en diversas ocasiones se le denomina directamente por la marca comercial.

Alcohol. Se presentan dos tipos de consumo: uno social y normalizado en bares, discotecas, fiestas y comidas, y otro a cargo de personajes alcohólicos. Almodóvar muestra dos tipos de alcohólicos, unos conscientes de su patología, que utilizan el alcohol como estrategia de afrontamiento, y otros que han adoptado la bebida como modo de vida. Estos dos tipos de patología alcohólica quedan plasmados en las figuras de Leo y Ángel en el film "La flor de mi secreto". La actitud ante las intoxicaciones etílicas es desfavorable. A menudo, al igual que el tabaco, el alcohol es denominado por su marca.

Psicofármacos. Ansiolíticos, tranquilizantes, somníferos y anfetaminas son objeto de un consumo puntual y de un consumo abusivo con riesgo de dependencia, como es el caso de Gloria en "¿Qué he hecho yo para merecer esto?". La presencia de psicofármacos en los hogares de los protagonistas es habitual y se presenta de modo normalizado. En "Átame" se muestra el mercado ilegal de los mismos. Es frecuente la denominación de los psicofármacos por su nombre comercial.

Estimulantes menores. Su consumo se presenta siguiendo los modelos de consumo de la sociedad española, en el desayuno, a media tarde o se ofrece a las visitas. El café forma parte de la vida diaria de las familias y de los personajes de las películas. El té aparece esporádicamente.

Heroína y derivados. La heroína se usa como vía de escape de la realidad, para relajarse y obtener tranquilidad e incluso para adelgazar, como sucede en "¿Qué he hecho yo para merecer esto?". La actitud del director frente a esta sustancia evoluciona desde de la completa aceptación hasta mostrar las consecuencias negativas de su adicción, como las sobredosis y envenenamientos, la infección por el Virus de Inmunodeficiecia Humana, la marginación y la degradación social. En diferentes películas se presentan los barrios y contextos donde es habitual este tipo de droga, el prototipo de traficante/vendedor de sustancias ilegales y, los diferentes modos de administración y vías de consumo. También es importante destacar que se alude a ella mediante jerga de la calle, tal como "choca" o "burra". Los derivados opiáceos son consumidos mayoritariamente en forma de fármacos, recetados siempre por facultativos. Este es el caso de medicamentos como Fiorinal con codeína o el Sosegon.

Cocaína. La cocaína se consume para evadirse y para aumentar el rendimiento físico y cognitivo de los personajes. Se presenta asociada a situaciones festivas y celebraciones, para mejorar el estado de ánimo, como estimulante, en situaciones estresantes o, simplemente, porque se dispone de ella (por ejemplo en la "La ley del deseo"). La cocaína no sufre las connotaciones peyorativas de la heroína, es más, su consumo se presenta de modo socialmente normalizado. En ninguna ocasión se observan las consecuencias negativas de su consumo crónico.

Cannabis. El objetivo de su consumo es el de obtener paz y tranquilidad en las siete películas en las que aparece.

Alucinógenos. Se consume mayoritariamente para abandonar la realidad cotidiana y acercarse a una nueva dimensión espiritual. Esta idea queda plasmada en la comunidad religiosa representada en "Entre Tinieblas".

\section{Personajes}

El cine de Pedro Almodóvar muestra diferentes patrones de consumo y de consumidores de drogas. Cualquier personaje, sea cual sea su edad, sexo, profesión o condición social, puede consumir o relacionarse con el mundo de las drogas. Del total de personajes que aparecen a lo largo de las 13 películas, 170 son consumidores o están relacionados directa o indirectamente con las sustancias adictivas. Destacan los consumos de personajes a las que socialmente y debido a su profesión no se les esta permitido, por ejemplo médicos, policías o religiosos. Por el contrario, sí aparece el prototipo de vendedor de sustancias adictivas ilegales. Los traficantes se presentan siempre en contextos marginales, con características y rasgos comunes (de baja clase social, negociantes y chantajistas, con el único objetivo de vender).

\section{Contexto}

Las sustancias legales se consumieron en todo tipo de situaciones y contextos, al igual que las ilegales y los psicofármacos no prescritos. Las sustancias adictivas, legales e ilegales, se consumieron en ámbitos laborales, lúdicos, íntimos, religiosos, etc. Destaca sin embargo, la venta y consumo de estas últimas en plazas y calles de grandes urbes, zonas marginales y centros penitenciarios.

\section{Sexo}

Respecto al género se observó que de los 170 personajes que consumieron sustancias adictivas, 78 (46\%) fueron mujeres y 92 hombres. Las mujeres consumieron o hablaron 1 hora, 28 minutos y 54 segundos de drogas legales y 16 minutos, 12 segundos sobre drogas ilegales. Por su parte, los hombres 
consumieron o hablaron 1 hora, 23 minutos, 9 segundos de drogas legales y, 8 minutos y 38 segundos de ilegales.

Las sustancias más consumidas por los personajes femeninos fueron, por este orden: alcohol, tabaco, estimulantes menores, psicofármacos, heroína y derivados, cocaína, cannabis y alucinógenos. Las drogas más consumidas por el sexo masculino fueron tabaco, alcohol, estimulantes menores, heroína y derivados, psicofármacos, cocaína, cannabis y alucinógenos (Figura 3).

\section{Figura 3. Consumo de sustancias adictivas según sexo y tiempo dedicado a cada una.}

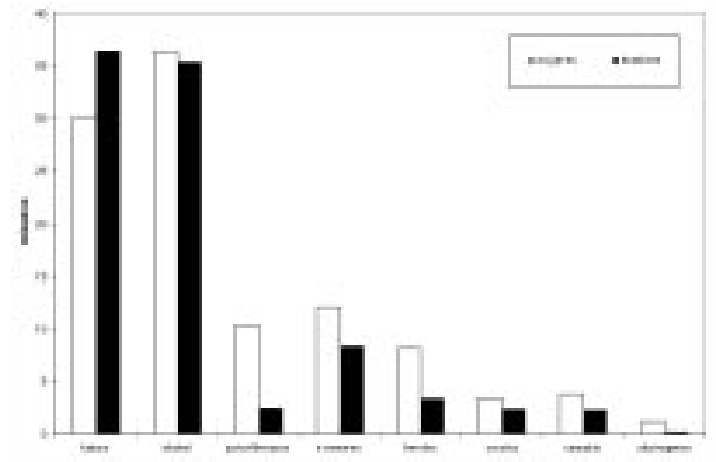

\section{DISCUSIÓN}

En la obra de Almodóvar se alude continuamente a drogas y a adicciones. La presencia de drogas legales, sobre todo alcohol y tabaco, es superior al de drogas ilegales, al igual que en otros estudios sobre películas españolas (García, 1999; Jové, 2000; Vidal, 1999), estadounidenses (Roberts y cols. 1999) y series de televisión del mismo país (Christensen, Kelly y Roberts, 2000). ¿Cómo se debe entender esta presencia continua de las drogas en el cine? Desde un punto de vista preventivo, la opinión preponderante en Estados Unidos es que se trata de un proceso sutil de normalización y aceptación del consumo de drogas a través de las películas dedicadas al público infantil y juvenil. En este sentido, "Pearl Harbour" (Michael Bay, 2001) es una película 'políticamente correcta' porque ningún protagonista aparece fumando. Ahora bien, en nuestra opinión el cine también es un reflejo de la sociedad en la que se produce, de sus usos y costumbres, y satanizar el consumo de drogas, como se ha hecho a veces con la violencia o la sexualidad, es solo una de las opciones.

De todas formas, es diferente mostrar un realidad en la que se consumen drogas a utilizar el cine para publicitar marcas de alcohol o tabaco. Esta técnica en publicidad se denomina product placement y es una práctica frecuente en series televisivas de producción española. Aunque en el cine de Almodóvar esta práctica es probablemente un recurso técnico para ganar realismo, debe señalarse que Sargent y cols. (2001) denunciaron la utilización del cine como instrumento propagandístico de las compañías tabaqueras. Estos autores analizaron las 25 películas más taquilleras de cada año en EE.UU de 1988 a 1997 (250 películas en total). Encontraron que se consumía tabaco en 217 $(87 \%)$ y que en 70 estaba presente la marca de los cigarrillos y que en 33 de éstas, la marca aparecía más de una vez. Las marcas que aparecían con más frecuencia coincidían con las compañías tabaqueras más anunciadas en EE.UU. En el $40 \%$ de las películas se presentaba el logotipo de la marca de tabaco en prendas de vestir o en vallas publicitarias y en un $4 \%$ se realizó alguna alusión verbal a la compañía tabacalera. Todo ello llevó a sugerir la concordancia entre los objetivos publicitarios de las compañías tabaqueras y las acciones de la industria cinematográfica. No olvidemos que en España las series televisivas se utilizan para publicitar productos y que la lógica de mercado no distingue entre una marca de cerveza y una de detergente.

La sustancia ilegal más representada, aunque a mucha distancia de tabaco y alcohol, es la heroína, seguida de la cocaína y el cannabis. Mientras que las drogas legales se suelen denominar por su marca comercial, para las ilegales se utilizan palabras propias de la jerga adictiva. A diferencia de las legales, en muchas ocasiones se alude a las mismas pero no se presenta su consumo o su imagen. Almodóvar parece huir del impacto emocional que buscan otros directores al presentar escenas de consumo de drogas por vía endovenosa (véase por ejemplo, "El Pico" (1983) de Eloy de la Iglesia o "Trainspotting" (1995) de Danny Boyle). Las drogas se utilizan para caracterizar el personaje y su contexto sin ser nunca el tema central de su propuesta.

La actitud de Almodóvar hacia las drogas ilegales evoluciona desde una actitud contracultural propia de la 'movida madrileña', incitadora al consumo de algunas sustancias ilegales, hasta mostrar sus consecuencias más negativas y trágicas. A lo largo de la filmografía se puede observar como varía la actitud hacia opiáceos y derivados, posiblemente debido a la aparición del Virus de Inmunodeficiencia Humana y del SIDA aunque no sucede lo mismo con otras sustancias ilegales, como la cocaína o el cannabis. En este sentido, Almodóvar en sus últimas películas refleja la opinión social sobre la heroína y sus consecuencias considerándola un problema social.

Almodóvar, como otros directores, tal como resaltan Christensen y cols. (2000) y Roberts y cols. (1999), presenta el alcohol de forma agradable y no sancionadora. El alcohol con moderación no es perjudicial, solo 
las personas que pretenden destruirse con él o aquellas que tienen graves problemas psicológicos o de marginación pueden convertirse en alcohólicos. Desde finales de los setenta ya se ha destacado el efecto distorsionador del cine en las representaciones del 'bebedor' y del 'borracho' (Grant, 1979), el estigma del alcoholismo femenino (Harwin y Otto, 1979) y en las causas del alcoholismo (moral, biológico, psicológico y social) (Lewington, 1979). Almodóvar presenta dos tipos distintos de enfermedad alcohólica. En la primera, el personaje utiliza el alcohol como estrategia de afrontamiento frente a una realidad de la que no puede escapar, es consciente de su enfermedad y la racionaliza; mientras que, en la segunda, el alcohólico ha adoptado el acto de beber de forma abusiva como una expresión más de su propia personalidad, como parte de su carácter, sin consciencia de su adicción. En este tema, Almodóvar parece abundar en la opinión de que el alcoholismo es una opción racional y deliberada o una consecuencia de una personalidad patológica.

No solamente las drogas generan dependencia y, por ello, Almodóvar introduce las adicciones conductuales, en "Qué he hecho yo para merecer esto", el personaje de la abuela no puede dejar de consumir dulces y "burbujas" y en "La flor de mi secreto" el personaje de Leo no puede romper la relación con su marido. Muchas veces, los héroes de Almodóvar se enganchan a las drogas o al alcohol antes de engancharse al amor (Strauss, 2001).

En el cine de Almodóvar no existen personajes prototípicos asociados al consumidor de drogas, a excepción de los personajes que representan a los traficantes de sustancias ilegales. Cualquier personaje puede consumir drogas legales o ilegales, siendo indiferente su edad, sexo, clase social o profesión, diferenciando entre consumidores sociales y adictos. Destacan sobre los demás personajes consumidores los miembros de una comunidad religiosa, los consumos realizados por figuras de autoridad y los realizados por médicos y policías en el ejercicio de su profesión. La única droga que genera dependencia es la heroína mientras que las otras drogas ilegales pueden consumirse esporádicamente. Curiosamente, Almodóvar presenta dos protagonistas adictas a la heroína (Yolanda de "Entre tinieblas" y Elena de "Carne trémula") capaces de superar su adicción (Cabrera, 2001).

En cuanto a la diferencia entre sexos, y en contraposición a los estudios sobre el cine de Vicente Aranda (Jové, 2000) y sobre las películas del "Oeste" (López, 1999), muchos personajes femeninos consumen drogas legales e ilegales, incluso, la presencia de este consumo en la pantalla es superior a la de los hombres. Las tres drogas más consumidas por los personajes femeninos son, por este orden: el alcohol, el tabaco y el café; mientras que el orden para los hombres es tabaco, alcohol y café.

En conclusión, apuntar la fecundidad metodológica del uso de muestras de películas, lo que nos permite aproximarnos a la representación social de las drogas. El consumo de drogas y la adicción no es tema central sino un recurso para caracterizar a los personajes y su contexto. En Almodóvar, las drogas legales (alcohol y tabaco, fundamentalmente) se representan más frecuentemente que las ilegales (heroína y cocaína), las mujeres consumen más drogas que los hombres y las únicas drogas que generan dependencia son el alcohol, el tabaco y la heroína. Almodóvar evoluciona en su opinión sobre la heroína, cuya adicción pasa a ser peligrosa y en algunos casos mortal, siendo siempre muy permisivo con el consumo de cocaína y alcohol, hasta el punto de presentar la adicción al alcohol como una opción racional o como el fruto de una psicopatología previa. Por último, no se debe infravalorar el riesgo de utilizar el cine como elemento publicitario de drogas legales.

\section{REFERENCIAS BIBLIOGRÁFICAS}

Cabrera, M. (2001). El consum de drogues il.legals en les pel.lícules de Pedro Almodovar. Barcelona: Universitat Ramon Llull, proyecto de licenciatura (manuscrito no publicado).

Carnall, D. (1998). Smoking on celluloid. British Medical Journal, 316, 712

Christenson, P. G., Kelly, M. y Roberts, D.F. (2000). Substance use in popular prime-time television. The National. Clearinghouse for Alcohol and Drug Information. Disponible en la dirección de Internet: http://wWw. health.org/govstudy/tvmediastudy.

Costa Badia, P. y Pérez Tornero, J. Ma. (1989). Droga, televisión y sociedad. Comunidad y Drogas. Monografía $\mathrm{n}^{\circ} 8$. Madrid: Ministerio de Sanidad y Consumo.

Everett, S.A., Schnutz, R.L. y Tribble, J.L. (1998). Tobbaco and alcohol use in top-grossing American films. Journal Community Health, 23, 317-324.

Gallero, J. M. (1991). Solo se vive una vez. Esplendor y ruina de la movida madrileña. Madrid: Ediciones Ardora.

García, M. (1999). El consumo de drogas en la cinematografía española de 1997. Barcelona: Universitat Ramon Llull, proyecto de licenciatura (manuscrito no publicado).

García de León, Mª. A. y Maldonado, T. (1989). Pedro Almodóvar, la otra España cañí. Ciudad Real: Diputación Provincial de Ciudad Real.

Goldstein, A.O., Sobel, R.A. y Newman, G.R. (1999). Tobbaco and alcohol use in G-rated children's animated films. Journal of American Medical Association, 281, 1131-1136.

González, R. y Donaire, I. (1986). El cine como reflejo de actitudes ante el alcohol. Revista del Hospital Psiquiátrico de La Habana, 27, 377-383. 
González, R. y Cisneros, A. (1988). Patrones de consumo etílico en el cine: estudio de una muestra de filmes cubanos y de otros países latinoamericanos. Revista del Hospital Psiquiátrico de La Habana, 29, 41-45.

Grant, M. (1979). The alcoholic as hero. En J. Cook y M. Lewington (Eds.), Images of alcoholism (pp. 30-36). London: British Film Institute.

Harvin, J. y Otto, S. (1979). Women, alcohol and the screen. En J. Cook y M. Lewington (Eds.), Images of alcoholism (pp. 37-50). London: British Film Institute.

Hazán, A. R., Lipton, H. L. y Glantz, S.A. (1994). Popular films do not reflect current tobacco use. American Journal of Public Health, 84, 998-1000.

Holguín, A. (1994). Pedro Almodóvar. Madrid: Cátedra.

Jovè, M. (2000). Anàlisi del consum de substàncies addictives en el cinema de Vicente Aranda (1964-1999). Barcelona: Universitat Ramon Llull, proyecto de licenciatura (manuscrito no publicado).

Lewington, M. (1979). An overview. En J. Cook y M. Lewington (Eds.), Images of alcoholism (pp. 22-29). London: British Film Institute.

López, S. (1999). L'alcohol a les pel.lícules de l'oest: època 1930 a 1960. Barcelona: Universitat Ramon Llull, proyecto de licenciatura (manuscrito no publicado).

Mclntosh, W.D., Bazzini, D.G., Smith, S.M. y Wayne, J.M. (1998). Who smokes in Hollywood? Characteristics of smokers in populars films from 1940 to 1989 . Addictive Behaviors, 23, 395-398.

Roberts, D.F., Henriksen, L., Christenson, P.G. y Kelly, M. (1999). Substance use in popular movies and music. Disponible en la dirección de internet: http://www. health.org/govstudy/mediastudy/default.aspx.

Rodríguez, E. (2000). Cine y drogas. Adicciones, 12, 48.

Sánchez Carbonell, X. (1999). Drogas y cine: una relación de ficción. Centro de Documentación de Drogodependencias (boletín), 57, 1.

Sargent, J.D., Tickle, J.J., Beach, M.L., Dalton, M.A., Ahrens, M. B. y Heatherton, T. F. (2001). Brand appearences in contemporary cinema films and contribution to global marketing of cigarrettes. The Lancet, 357 (29-32).

Stockwell, T. F. y Glantz, S. A. (1997). Tobacco use is increasing in popular films. Tobacco Control, 6, 282-284.

Stockwell, T. F. (1998). Smoking in the movies remained high in 1997 [carta al editor]. Tobacco Control, 7, 441.

Strauss, F. (2001). Conversaciones con Pedro Almodóvar. Madrid: Ediciones Akal.

Uris, P. (1995). Alucinema: las drogas en el cine. Barcelona: Royal Books.

Vidal, L. (1999). Anàlisi de la presència de substàncies addictives a les pel/lícules guanyadores del premi Goya com a millor pel.lícula (1994-1997). Barcelona: Universitat Ramon Llull, proyecto de licenciatura (manuscrito no publicado). 